\title{
Caracterização morfodinâmica e usos na faixa praial da área do Grupo de Bacias Costeiras 01 do estado de Sergipe
}

\author{
Morphodynamic characterization and uses at the coast area on completeness \\ of coastal watershed Group 01 of the state of Sergipe
}

\author{
Alves $^{1}$, N. M. S.; Rodrigues ${ }^{2}$, T. K.; Barreto $^{3}$, S. A. \\ neisemare@gmail.com
}

\begin{abstract}
Resumo
O Grupo de Bacias Costeiras 01 (GC1) reúne as bacias dos rios Aningas e Sapucaia, ambas exorreicas. O GC1 drena os municípios de Pirambu, Pacatuba e Japaratuba estando inserido nas unidades geomorfológicas Tabuleiros Costeiros e Planície Costeira. Assim, possui uma faixa praial de $16 \mathrm{~km}$, com atrativos de lazer e turísticos. Este trabalho tem por objetivo caracterizar a morfodinâmica atuante e usos na faixa praial do GC1. Na realização foram adotadas as metodologias propostas Leatherman (1997), MMA (2001) e Bush (1999). Os trabalhos de campo possibilitaram observar a ação dos processos costeiros, as características ambientais, os tipos de uso e ocupação e coletar sedimentos, a cada quilometro da face praial. Em laboratório, as amostras de sedimentos foram analisadas seguindo o procedimento padrão. A integração dos resultados permitiu classificar a praia como dissipativa, predominando os sedimentos arenosos finos. Entretanto, nos setores próximos às desembocaduras dos rios foram observadas características morfodinâmicas de praia intermediária.
\end{abstract}

Palavras-chave: Caracterização morfodinâmica, parâmetros físicos, geoindicadores.

\begin{abstract}
The Group of Coastal Basins 01 (GC1) brings together the basins of Aningas and Sapucaia rivers, both exorreicas. The GC1 drains the municipalities of Pirambu, Pacatuba and Japaratuba and being inserted in geomorphological units - tableland and Coastal Plain. So it has a praial range of $16 \mathrm{~km}$, with attractive leisure and tourism. This work aims to characterize the morphodynamic active and uses the praial range of GC1. In carrying out the proposed methodologies were adopted Leatherman (1997), MMA (2001) and Bush (1999). The field work allowed to observe the action of coastal processes, environmental characteristics, types of use and occupation and collect sediment, every kilometer of praial face. In laboratory the sediment samples were analyzed following the standard procedure. The integration of the results allowed to classify the beach as dissipative, predominantly fine sandy sediments. However, in the areas near the mouths of rivers morphodynamics intermediate beach were observed.
\end{abstract}

Keywords: Morphodynamic characterization, physical, biological indicators.

\section{INTRODUÇÃO}

A linha de costa foi definida por Suguio (1992) como “[...] o limite entre o continente e a porção adjacente ao mar onde não há ação efetiva das ondas de alcance máximo, concretizando-se pela presença de falésias no limite entre a vegetação e a praia, ou por qualquer outra feição que marque o início da área continental”.

Segundo Hoefel (1998), diversos fatores atuam na dinâmica costeira destacando-se ondas, vento, correntes litorâneas e marés, além de ações antrópicas, que na sua interação influenciam na variabilidade da linha de costa.

\footnotetext{
${ }^{I}$ Neise Mare de Souza Alves, Departamento de Geografia, Universidade Federal de Sergipe, São Cristovão - SE, Brasil

${ }^{2}$ Tais Kalil Rodrigues, Departamento de Geografia, Universidade Federal de Sergipe, São Cristovão - SE, Brasil

${ }^{3}$ Sinthia Araujo Barreto, Departamento de Geologia, Universidade Federal de Sergipe, São Cristovão - SE, Brasil
} 
As praias vêm sofrendo uma crescente descaracterização em razão da ação antrópica, incluindo-se a ocupação desordenada, os despejos de efluentes domésticos e industriais transportados pelos rios e lançados ao mar, que podem comprometer a balneabilidade e o descarte de resíduos sólidos que com frequência são abandonados pela população a utiliza para o lazer. Além desses fatores, merecem destaque a crescente especulação imobiliária, mineração, retirada de areia de praias e dunas e o crescimento do turismo sem planejamento. O emprego de estratégias para a conservação dos habitat associada à implantação de programas de educação ambiental serviria como medida de proteção às paisagens e aos ecossistemas da zona costeira (CUNHA, 2005).

O crescente adensamento populacional na zona costeira se constitui um problema de gestão ambiental, seja pela grande atratividade turística ou pelas possibilidades da expansão das atividades econômicas. Consequentemente, as bacias hidrográficas e paisagens costeiras podem ficar comprometidas pela pressão do acelerado processo de urbanização e infraestrutura (POLETTE $e t$ al., 2000). Vale ressaltar que a bacia hidrográfica é um sistema onde todos os elementos naturais e o componente antrópico estão em permanente interação. Assim, qualquer mudança ocorrida em um deles afeta todo o sistema (CHRISTOFOLETTI, 1980).

Dentre os estudos realizados sobre a zona costeira do estado de Sergipe destaca-se o de Carvalho e Fontes (2006) que identificaram uma linha de costa com extensão de $163 \mathrm{~km}$ entre o rio São Francisco no limite norte e os rios Piauí/Real ao sul, caraterizada por uma diversidade de aspectos físicos, biológicos e socioeconômicos. Na planície costeira são encontrados ambientes estuarinos associados aos rios São Francisco, Japaratuba, Sergipe, Vaza Barris e Piauí/Real. Seguindo o padrão internacional de elevada densidade e produtividade no litoral, Sergipe apresenta significativa concentração populacional e de atividades produtivas na zona costeira, destacando-se na atualidade a carcinicultura nos estuários.

O Grupo de Bacias Costeiras 01 abrange os municípios de Pirambu, Pacatuba e Japaratuba no litoral norte do estado de Sergipe. Ele é formado pelas bacias hidrográficas dos rios Sapucaia e Aningas. Estes rios possuem suas nascentes nos bordos dos Tabuleiros Costeiros e deságuam no oceano, após percorrer um setor da planície costeira onde se encontra a Reserva Biológica (REBIO) de Santa Isabel, uma Área de Preservação Permanente (APP), criada em 1998 (Figura 01). A Unidade inclui áreas dos municípios de Pacatuba e Pirambu onde ocorrem os ecossistemas manguezal, praial, dunar e áreas úmidas. Esses ecossistemas se encontram em avançado estágio de degradação por tipos de uso inadequados. A REBIO se constitui um atrativo turístico em razão de sua finalidade que é preservar as condições ambientais e manter um projeto educativo. Embora, localmente, se evidencie conflitos de interesses com a população local, em relação ao tipo de uso (ICMBIO, 2010). 
Diante desse contexto, foi escolhido como objeto de estudo a faixa praial integrada ao Grupo de Bacias Costeiras 01, para realizar uma caracterização morfodinâmica e ambiental. Ela possui 16 km de linha de costa e está submetida a constante dinâmica pela ação de processos costeiros e antrópicos.

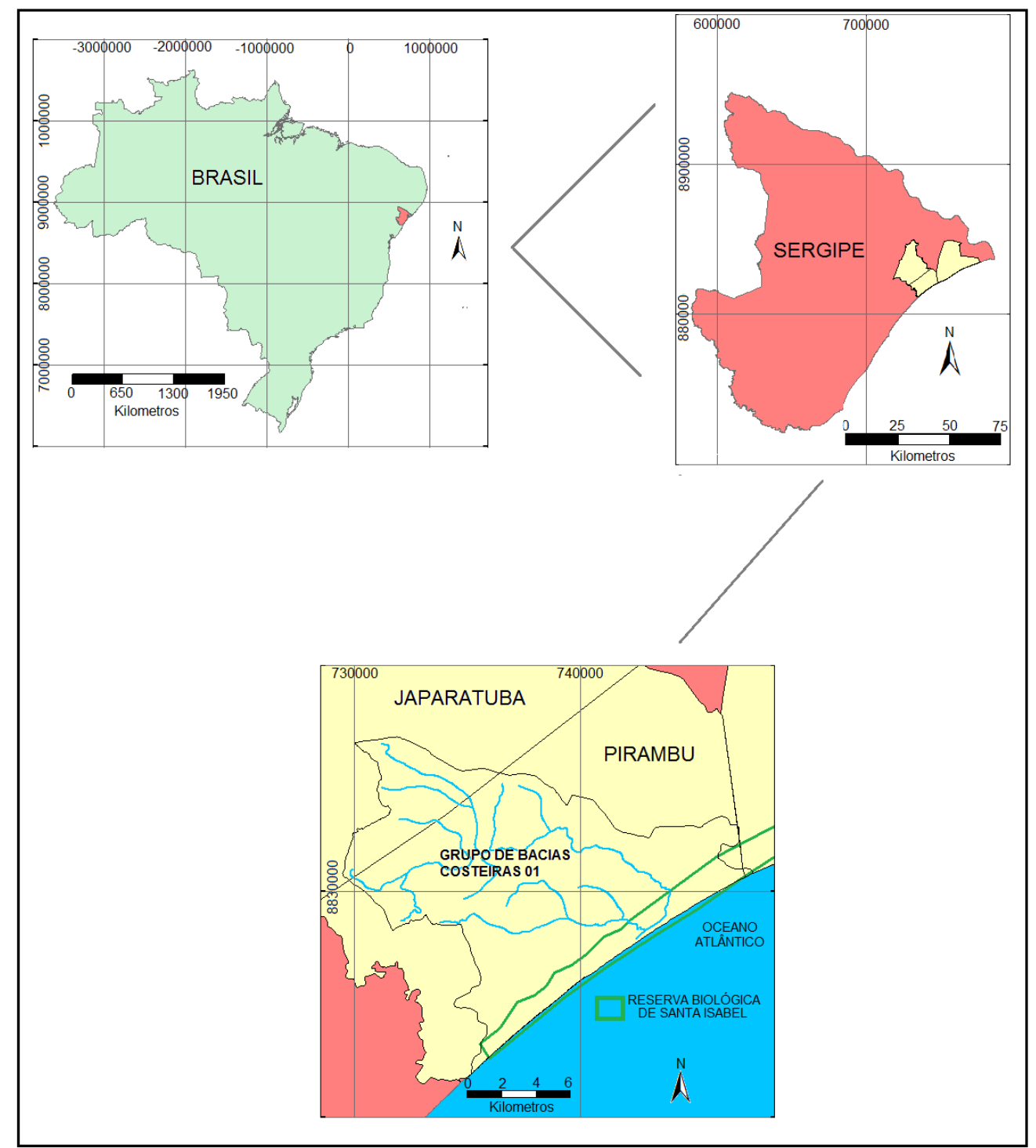

Figura 01 - Área de Estudo. Fonte: modificado do Atlas SRH/SE.

\section{METODOLOGIA}

Para a realização deste trabalho foi feito um levantamento bibliográfico referente ao tema e trabalhos de campo que contribuíram para conhecer e analisar aspectos da área de estudo - a dinâmica costeira, impactos da ocupação antrópica, as feições naturais e culturais, nível de urbanização da zona de pós-praia, encalhes na região de face de praia, parâmetros oceanográficos e de antepraia indicativos de erosão, progradação e equilíbrio do segmento da linha de costa, coleta de sedimentos, tendo no total 16 pontos amostrais (Figura 02). 


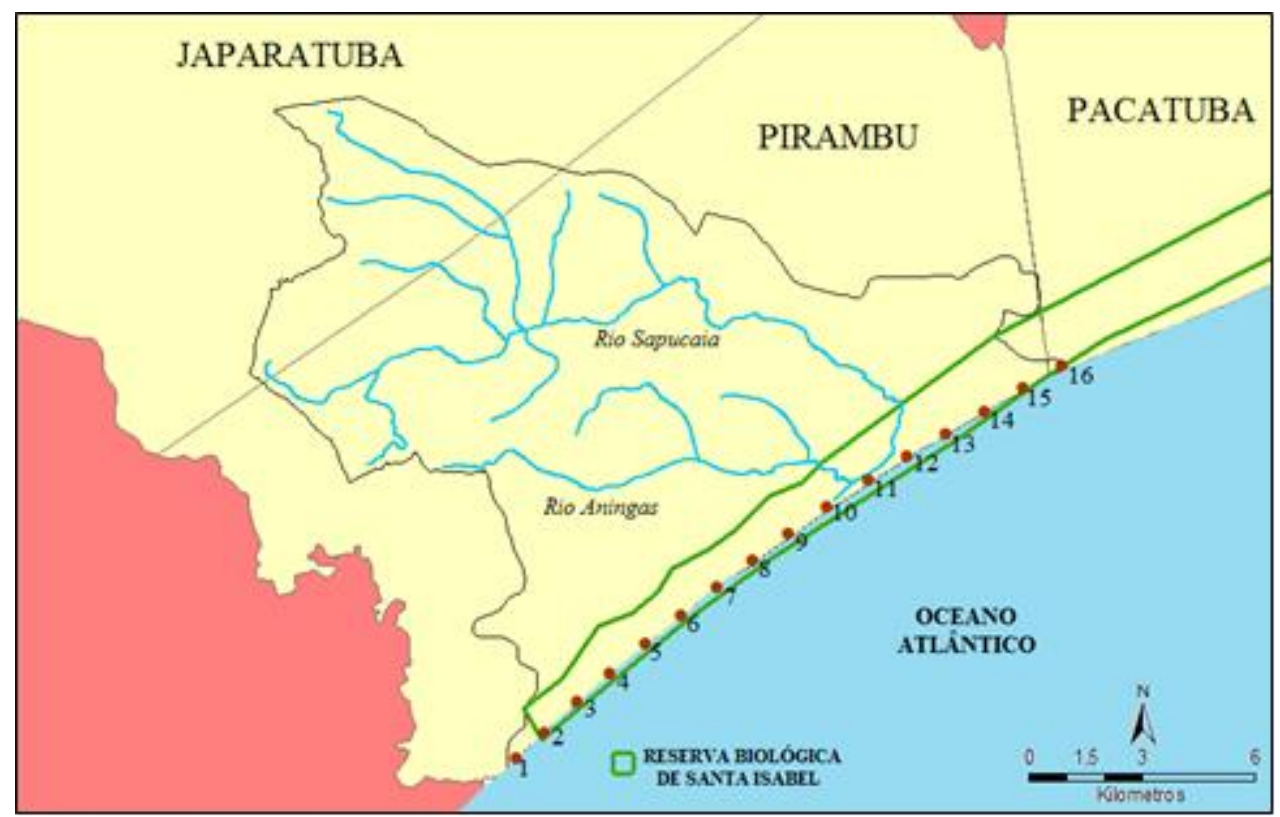

Figura 02 - Pontos de coletas. Fonte: modificado do Atlas SRH/SE.

No trabalho de campo foi realizado, a cada quilometro de linha de costa a coleta superficial de $100 \mathrm{~g}$ de sedimento, essas amostras dos sedimentos foram analisadas quanto a sua textura, passando pelo procedimento de lavagem para a retirada dos sais solúveis e colocadas para secar em estufa, a uma temperatura média de $50^{\circ} \mathrm{C}$. Após esse processo, as amostras foram quarteadas manualmente e peneiradas com a utilização de um agitador de peneiras tipo Rotap, em um conjunto de peneiras fracionadas em intervalos de 0,5 Phi, as frações granulométricas retiradas em cada peneira foram pesadas em uma balança de precisão. Os dados obtidos nesse processo foram inseridos no programa SysGran 2.2, para o cálculo de parâmetros estatísticos e classificação dos sedimentos (Tabela 01).

Tabela 01 - Classificação granulométrica da areia, Escala de Wentworth.

\begin{tabular}{c|c}
\hline Diâmetro (MM) & Classificação \\
\hline 4,00 a 2,00 & Grânulo \\
\hline 2,00 a 1,00 & Muito grossa \\
\hline 1,00 - 0,500 & Grossa \\
\hline 0,500 a 0,250 & Média \\
\hline 0,250 a 0,125 & Fina \\
\hline 0,125 a 0,0625 & Muito fina \\
\hline
\end{tabular}

Fonte: (SUGUIO, 1973).

As informações obtidas anteriormente foram analisadas possibilitando a caracterização da área estudada, assim como a criação de um banco de dados geoambientais, o qual poderá contribuir para a gestão dessa região e para o desenvolvimento de outros trabalhos.

$\mathrm{Na}$ caracterização ambiental da linha de costa foram levantadas as seguintes informações: i) meio físico: tipos de litoral, tipos de linha de costa, situação da praia média e da face de praia, 
granulometria dos sedimentos, declividade da face de praia, largura da praia e classificação morfodinâmica das praias; ii) meio antrópico: urbanização da linha de costa, concentração de barracas de praia e presença de lixo e iii) meio biológico: presença de cobertura vegetal na linha de costa (LEATHERMAN, 1997).

Para a identificação do tipo de litoral utilizou-se a classificação do MMA (2001), que estabelece as seguintes categorias: i) litoral exposto: é sujeito a grandes ondas e fortes correntes de maré durante todas as estações climáticas do ano. Essa situação normalmente acontece ao longo de litorais expostos à ação direta das ondas de tempestades; ii) litoral semi-exposto: apresenta padrões sazonais na frequência de tempestades e altura de ondas. É definido para as costas que são protegidas apenas das ondas de tempestades; iii) litoral protegido: está protegido de ondas, exceto em eventos ocasionais, compreendendo todos os segmentos da costa que se encontram em enseadas e situações onde não estão diretamente voltados ao oceano.

No que se refere à morfodinâmica foi adotada a classificação de Wright \& Short (1984), que identificaram os seguintes estágios com base em observações feitas em praias da Austrália: dissipativo, refletivo e quatro tipos intermediários. O estágio dissipativo é caracterizado por alta energia de ondas, zona de surfe bem desenvolvida, apresenta inclinação suave e presença granulometria fina. O estágio refletivo é definido por apresentar praias com baixa energia de ondas, zona de surfe pouco desenvolvida, face de praia estreita com granulometria grossa e alta declividade. As praias em estágio intermediário possuem larguras menores que as dissipativas, sedimentos de granulometria média a grossa e inclinação moderada da face de praia, onde geralmente apresenta cúspides e um berma.

\section{RESULTADOS E DISCUSSÃO}

\subsection{Caracterização dos parâmetros físicos da área de estudo}

$\mathrm{Na}$ área estudada, o tipo de litoral é o exposto, estando sujeita a fortes correntes de maré em todas as estações e receber a ação direta das ondas (Figura 03 A). Além disso, a linha de costa é bordejada por depósitos arenosos correspondentes a terraços marinhos ou cordão duna (Figura 03 B).
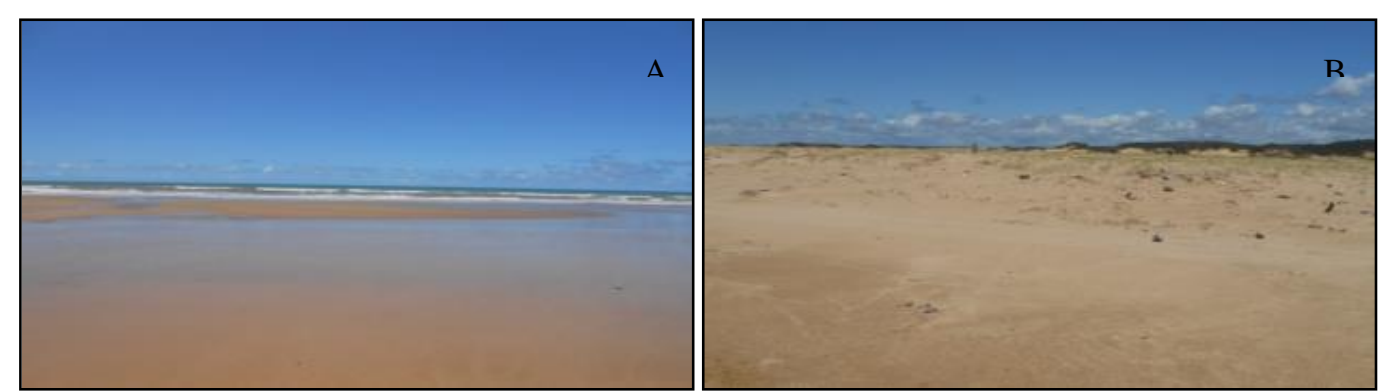

Figura 03 - A: Tipo de litoral exposto da área de estudo; B: Linha de costa bordejada por depósitos arenosos.

Fonte: Autora 
$\mathrm{Na}$ área, os terraços marinhos contatam com as dunas frontais ou escarpas erosivas, com declividades na face de praia variando entre 2 a 4 graus em todos os pontos e a largura da face de praia entre 45 e 95 metros (Tabela 02).

Tabela 02 - Declividade, Largura da face praial, Classificação granulométrica e Classificação morfodinâmica da praia.

\begin{tabular}{|c|c|c|c|c|}
\hline $\begin{array}{c}\text { Pontos de } \\
\text { coleta }\end{array}$ & $\begin{array}{l}\text { Declividade } \\
\text { (em graus) }\end{array}$ & $\begin{array}{c}\text { Largura da face } \\
\text { praial (m) }\end{array}$ & $\begin{array}{c}\text { Classificação } \\
\text { granulométrica }\end{array}$ & $\begin{array}{c}\text { Classificação } \\
\text { morfodinâmica dos } \\
\text { pontos praiais }\end{array}$ \\
\hline 1 & -- & 64 & Areia fina & Dissipativa \\
\hline 2 & -- & 61 & Areia média & Intermediária \\
\hline 3 & 2 & 58 & Areia média & Intermediária \\
\hline 4 & 2 & 78 & Areia fina & Dissipativa \\
\hline 5 & 2 & 71 & Areia fina & Dissipativa \\
\hline 6 & 3 & 70 & Areia média & Intermediária \\
\hline 7 & 2 & 91 & Areia fina & Dissipativa \\
\hline 8 & 2 & 62 & Areia fina & Dissipativa \\
\hline 9 & 4 & 63 & Areia fina & Dissipativa \\
\hline 10 & 2 & 95 & Areia fina & Dissipativa \\
\hline 11 & 2 & 62 & Areia fina & Dissipativa \\
\hline 12 & 2 & 76 & Areia fina & Dissipativa \\
\hline 13 & 2 & 79 & Areia fina & Dissipativa \\
\hline 14 & 3 & 73 & Areia fina & Dissipativa \\
\hline 15 & 2 & 60 & Areia fina & Dissipativa \\
\hline 16 & 3 & 45 & Areia fina & Dissipativa \\
\hline
\end{tabular}

Fonte: Elaborado pela autora.

Segundo Komar (1976), dois fatores são determinantes no controle da granulometria dos sedimentos da praia: a fonte dos sedimentos, que pode ser a plataforma interna, falésias ou desembocaduras de rios, e, a energia de ondas, que incide na face da praia. O tamanho médio do grão pode ser classificado, segundo a escala granulométrica de Wertworth em granulo, areia muito grossa, areia grossa, areia média, areia fina, areia muito fina, silte e argila (SUGUIO, 1973).

Os 16 pontos amostrais da face praial estudada indicaram características semelhantes nos parâmetros analisados. De modo geral, os pontos apresentaram maior quantidade de areia fina e bem selecionada, à exceção de três situados nas proximidades das desembocaduras dos rios, que exibiram maior teor de areia média e moderadamente selecionada, devido à dinâmica costeira atuante que mistura as frações granulométricas (Tabela 02). No que tange à classificação por 
assimetria dos grãos, predominaram os moderadamente simétricos, alguns pontos com assimetria positiva se justifica devido à descarga de sedimentos próxima à desembocadura do rio Sapucaia.

A classificação morfodinâmica, com base em Wright \& Short (1984), permitiu a seguinte constatação: estágio dissipativo nos pontos $1,4,5,7,8,9,10,11,12,13,14,15$ e 16, pela presença de granulometria fina, maior largura da face de praia, inclinação suave e zona de surfe bem desenvolvida; os pontos 2, 3 e 6 apresentaram características intermediárias, com granulometria média e menor largura de face de praia, em razão da proximidade das desembocaduras dos canais fluviais, que em períodos de maior vazão alteram as características no ambiente praial (Tabela 02).

\subsection{Análise dos Geoindicadores}

O uso de geoindicadores possibilita o monitoramento do comportamento da linha de costa, através de observações de feições que indiquem erosão (escarpas nas dunas frontais, estruturas antrópicas na face de praia ou na antepraia, estruturas de contenção, lama de manguezal aflorando na praia, etc.), progradação (presença de bermas, dunas frontais bem desenvolvidas, etc.) e equilíbrio (presença de escarpas vegetadas e a ausência de sobrelavagem) na área em estudo.

$\mathrm{Na}$ área de estudo, para os 16 pontos analisados foram obtidos os seguintes resultados: 1 e 6 estavam em progradação; 2, 3, 4, 5, 8, 10 e 12 em equilíbrio; e os pontos 7, 9, 11, 13, 14, 15 e 16 em erosão (Figura 04). Essas características evidenciam que diferentes fatores influenciam na dinâmica costeira afetando as feições da face praial e a variação da linha de costa.

A dinâmica das marés, dependendo do seu alcance, pode contribuir para a erosão ou para a progradação da linha de costa, sendo o primeiro processo resultante da sobrelavagem da face e bermas praiais com a retirada de sedimentos e da vegetação, e, o segundo, pelo acúmulo de sedimentos, que propicia a formação de bermas.

\subsection{Uso e ocupação da área em estudo}

A área de estudo correspondente a linha de costa do Grupo de Bacias Costeiras 01, está inserida na área da Reserva Biológica (REBIO) de Santa Isabel, uma Área de Preservação Permanente (APP), que foi criada com o intuito de preservar ecossistemas costeiros, compostos por vegetação de restinga, cordões de dunas móveis e fixas, lagoas permanentes e temporárias e ambientes estuarinos. Além disso, abriga o maior sítio reprodutivo da tartaruga marinha Lepidochelys olivacea (tartaruga oliva), no território brasileiro. 

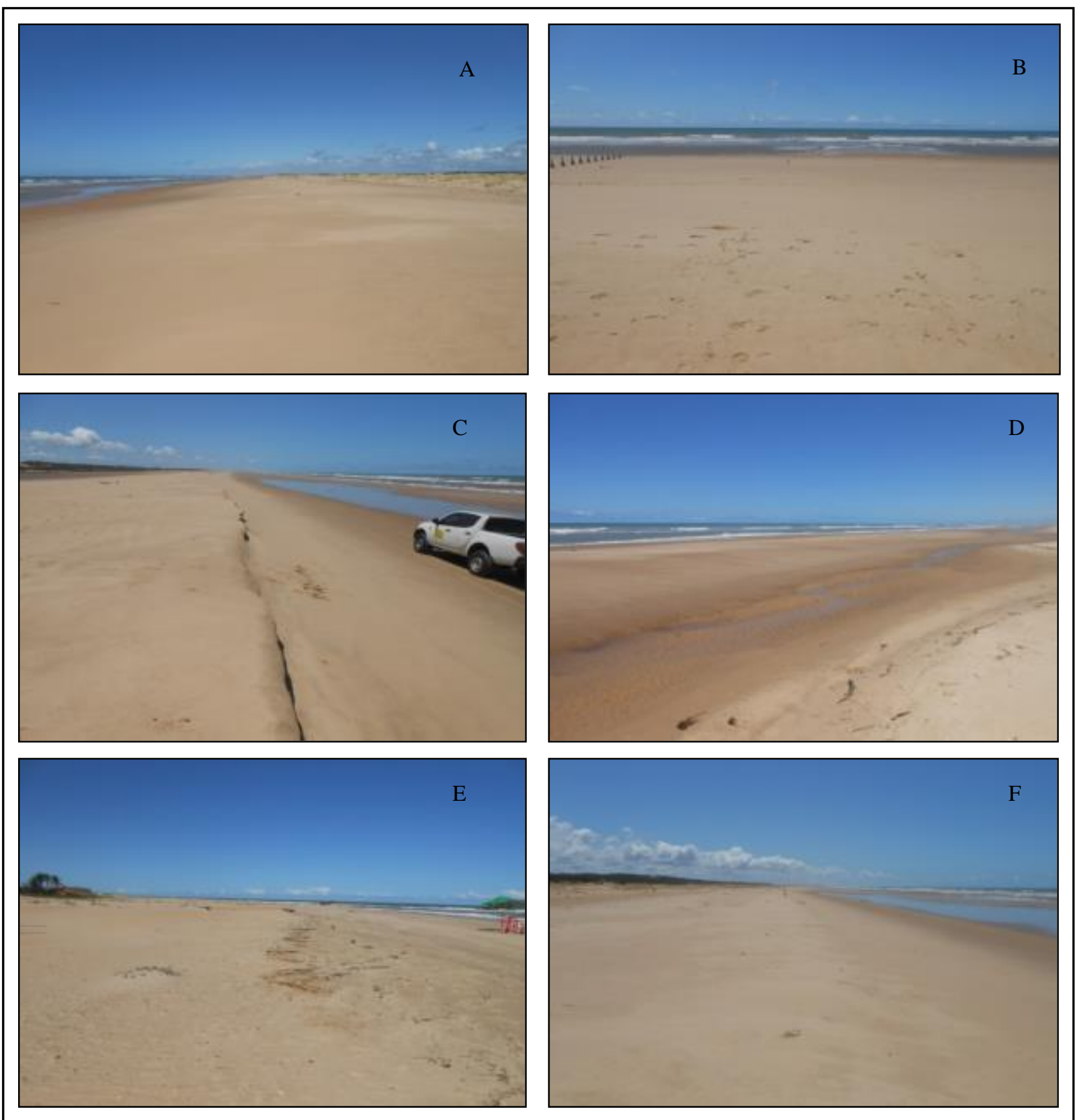

Figura 04 - Pontos em equilíbrio: (A) 4 e (B) 2; Pontos em erosão: (C) 11 e (D) 15; Pontos em progradação: (E) 1 e (F) 6. Fonte: Autora

Em atividade de campo, foram observadas atividades antrópicas que ocorrem no entorno da área estudada - piscicultura, carcinicultura, agropecuária e cocoicultura. São evidentes sinais de tráfego de veículos na faixa praial, ação que põe em risco o trânsito de tartarugas que vêm desovar na costa. 


\section{CONSIDERAÇÕES FINAIS}

Diante de toda a análise e estudo que foi feita na linha de costa do Grupo de Bacias Costeiras 01, pode-se perceber a partir da análise morfológica que a área de estudo apresenta o tipo de praia dissipativo, com exceção de pontos de desembocaduras e canais de rio. A área também apresenta alguns estágios de erosão e progradação em sua linha de costa, mas isso se explica através do tipo de litoral que a linha de costa apresenta, que é exposto e sofre influência das correntes de maré e ondas de tempestade ao longo do ano, e também através dos geoindicadores constatados na área de estudo. Em relação à intervenção antrópica, vários tipos de uso ilegal puderam ser constatados, o que demonstra o descaso no plano de conservação dos ecossistemas da área de estudo e que atualmente, apresenta-se frágil principalmente pelo uso indevido da área. Com isso, espera-se que este estudo contribua para a tomada de decisões e medidas que fortaleçam a conservação desse ambiente a partir do grau de vulnerabilidade em que se encontra e ações de manejo para que haja um aproveitamento da área sem degradação.

Com o auxílio dos geoindicadores constatados nesta área, pode-se colocar em prática o planejamento, gestão e estratégia de mitigação desses riscos constatados na área de estudo, como também a possibilidade de classificar as unidades naturais em função de sua susceptibilidade.

\section{REFERÊNCIAS}

BUSH, D. M.; NEAL, W. J.; YOUNG, R. S. \& PILKEY, O. H. Utilization of geoindicators for rapid assessment of coastal-hazard risk and mitigation. Ocean \& Coastal Management, v. 42, p. 647-670, 1999.

CARVALHO, M. E. S., FONTES, A. L. Caracterização geomorfológica da zona costeira do estado de Sergipe. In: VI Simpósio Nacional de Geomorfologia. Goiânia, 2006. 15p.

CHRISTOFOLETTI, A, 1936. Geomorfologia, 2a edição. São Paulo, Edgard Blucher, 1980.

CUNHA, E. M. S. Considerações gerais sobre a zona costeira. Capítulo III, 2005.

HOEFEL, F. G. Morfodinâmica de praias arenosas oceânicas: uma revisão bibliográfica. Itajaí: Editora da Univali, 1998. $92 \mathrm{p}$.

ICMBIO. Proposta de retificação e atualização dos limites da reserva biológica de santa isabel, no estado de Sergipe: relatório técnico. Ministério do Meio Ambiente. Pirambu, 2010.

KOMAR P.D. Beach processes and sedimentation. Prentice-Hall. In.: Englewood Cliffs, New Jersey, 1976. $429 \mathrm{p}$.

LEATHERMAN, S. P. Beach rating: a methodological approach. Journal of Coastal Research, Florida, v. 13, n. 1, p. 253-258, 1997.

MMA. Ministério do Meio Ambiente. Especificações e normas técnicas para a elaboração de cartas de sensibilidade ambiental para derrames de óleo. Brasília: Companhia Vale do Rio Doce, 2001. 23 p. 
POLETTE, M. Gerenciamento costeiro integrado e gerenciamento de recursos hídricos: como compatibilizar tal desafio. In: Interfaces da Gestão de Recursos Hídricos: Desafios da Lei de Águas de 1997 - Parte 4 : Gestão de Bacias e Gestão de Zonas Costeiras. 2000.

SERGIPE. - v.1 (1995). Aracaju: SEPLAG /SUPES, 2011 - v. 12 il. P 111.

SUGUIO, K. Dicionário de geologia marinha. T.A. Queiroz, São Paulo, SP, 1992. 171p.

SUGUIO, K. Introdução à sedimentologia. São Paulo: Edgard Blücher Ltda., 1973. 317 p.

WRIGHT, L. D.; SHORT, A. D. Morphodynamic variability of surf zones and beaches: a synthesis. Marine Geology, [SI], 56, p. 93-118, 1984.

\section{AGRADECIMENTOS}

Os autores agradecem a COPES/UFS pela concessão da bolsa de iniciação científica.

Recebido em: 14/08/2016

Aceito para publicação em: 01/10/2016 